\title{
20 Years Later: Reflections on the CES Student Evaluation Case Competition
}

\author{
Christine Sheppard \\ University of Waterloo \\ Ashley Baker \\ Memorial University of Newfoundland \\ Petra Lolic \\ Doctors of $B C$ \\ Shilpa Soni \\ University of Waterloo \\ Bea Courtney
}

\begin{abstract}
Since 1996, the Canadian Evaluation Society (CES) has held an annual case competition for college and university students. By 2016, a total of 1,132 students had participated. An online questionnaire was sent to 768 participants with available email addresses; eight additional participants entered the study after viewing an online posting. The questionnaire was completed by 112 former participants (response rate: 14\%). Findings suggest that participating in the case competition was a positive experience that led to an appreciation of evaluation, increased teamwork skills, and provided stronger résumés. Some indicated that participating influenced their choice of evaluation as a focus for their career.
\end{abstract}

Keywords: case competition, evaluation, students

Resumé : La Société canadienne dévaluation (SCE) organise depuis 1996 un concours annuel détudes de cas pour les étudiants universitaires et collégiaux. En 2016, un total de 1132 étudiants avait participé au concours pendant ses vingt premières années. Un questionnaire électronique a été envoyé à 768 participants dont l'adresse électronique était connue; huit autres participants se sont joints à l'enquête après en avoir pris connaissance en ligne. Le questionnaire a été rempli par 112 anciens participants (taux de réponse: $14 \%$ ). Selon les résultats, la participation au concours a été une expérience positive qui a mené à une plus grande maitrise de l'évaluation, à une amélioration des compétences pour le travail en équipe et à l'amélioration $d u$ curriculum vitae. Certains répondants ont indiqué que leur participation les a influencé dans leur choix de carrière.

Corresponding author: Christine Sheppard, University of Waterloo, 200 University Avenue West, Waterloo, ON, N2L 3G1; christine.sheppard@uwaterloo.ca

C 2019 Canadian Journal of Program Evaluation / La Revue canadienne d'évaluation de programme 34.1 (Spring / printemps), 118-130 doi: 10.3138/cjpe.42239 
Mots clés : concours, analyse de dossiers, évaluation, étudiants

The Student Evaluation Case Competition began in 1996 as an initiative of the Canadian Evaluation Society (CES) National Capital Chapter. In 2008, the CES National Council assumed responsibility for the competition, and it is now delivered in partnership with the Canadian Evaluation Society Educational Fund.

The case competition aims to provide students with an opportunity to enhance their knowledge of program evaluation by obtaining first-hand experience in evaluation planning and reporting, and applying evaluation theory to practice; to develop capacity for effective teamwork; and to receive recognition of excellence that will assist in securing evaluation-focused employment opportunities.

The competition takes place over two rounds and gives students an opportunity to prepare a response to a hypothetical request for proposal (RFP) for a realworld program (Obrecht, Porteous, \& Haddock, 1998; Williamson et al., 2016). The competition has utilized a variety of cases based on both government and community-based programs in diverse policy sectors and serving a wide variety of populations. Although every case is unique, common proposal requirements include creating or critiquing a program logic model, developing an evaluation matrix, identifying appropriate evaluation approach(es) and methods, recognizing challenges and potential solutions to carrying out the proposed evaluation, creating a stakeholder engagement and dissemination plan, and enabling the teams to demonstrate competencies for Canadian evaluation practice.

For the first round of the competition, teams of three to five students have five and a half hours to prepare their proposal, and submissions are judged by a panel of evaluators. The top three teams are invited to participate in the final round of the competition, where students have five hours to prepare their response to a new case. Proposals are presented live at the CES annual conference, and a winning team is selected by a panel of judges.

From 1996 to 2016, 298 teams of 1,132 students and 97 coaches from 31 colleges and universities across Canada participated in the competition. Competing teams were from Ontario (51.7\%), Quebec (14.8\%), Newfoundland and Labrador (14.1\%), Saskatchewan (9.1\%), British Columbia (4.0\%), Alberta (2.7\%) and Nova Scotia (2.3\%). There have been no teams from Prince Edward Island, New Brunswick, Manitoba, or the Territories. Students have participated from a variety of disciplines, including psychology, public health, business and management, public administration, education, nursing, planning and development, and social work. Over 200 students have participated more than once, and many schools and coaches support multiple teams each year.

The case competition is thought to be a valuable learning opportunity for students to gain experience applying evaluation theory, methods, and approaches (Obrecht et al., 1998), topics that university-level introductory and advanced evaluation course instructors feel are most important to teach when training new evaluators (Davies \& MacKay, 2014). By using a case-based approach, the competition enables students to gain hands-on experience applying the technical aspects 
of evaluation by creating an evaluation plan for a real-world program. This type of experiential learning is considered essential to evaluation education (Trevisan, 2004) and may help students overcome challenges applying evaluation theory to practice (Chouinard \& Boyce, 2017). The case competition may also better prepare students for employment, as it promotes skills related to evaluation theory, research design, and report writing, which are areas employers have identified as desirable but under-developed in new evaluators seeking jobs (Dewey, Montrosse, Schröter, Sullins, \& Mattox, 2008).

Past participants have reported that the case competition supports and strengthens the development of evaluation competencies (Williamson et al., 2016). For instance, the RFP may require students to demonstrate their understanding of the competencies for Canadian evaluation practice by illustrating how their proposal supports reflective, technical, situational, management and/ or interpersonal practice. This is noteworthy, as the ability to apply professional evaluation standards is an important competency that new evaluators need to master for successful practice (Galport \& Azzam, 2016). Demonstrating respect for stakeholders and serving the information needs of evaluation users are two other competencies that evaluators indicated are necessary for successful practice (Galport \& Azzam, 2016) and that are practiced through participation in the case competition (Williamson et al., 2016). For instance, past participants have reported that the competition encourages the development of an evaluation plan that considers the needs of the evaluation users and demonstrates understanding and respect for the uniqueness of the program, the participants, and other stakeholders (Williamson et al., 2016).

Interpersonal competencies have been cited as an area where evaluators feel they need additional training (Galport \& Azzam, 2016). Furthermore, interpersonal skills related to communication, collaboration, and conflict management are some of the most desired skills among employers hiring evaluators, but were ranked low among skills acquired through graduate training (Dewey et al., 2008). The case competition supports the development of these skills and others related to teamwork, problem solving, and time management (Nykiforuk et al., 2003; Seasons \& Myers, 2003). Specifically, the team environment requires students to identify individual strengths of teammates, provide constructive feedback to peers, and integrate work and ideas to create a cohesive evaluation plan (Williamson et al., 2016).

Engagement in professional activities, including being members of a professional evaluation organization and attending conferences, was identified as one of the most important educational experience among graduate students in evaluation (Dillman, 2012). The case competition supports these educational experiences by providing beneficial contacts and networking opportunities with their local CES chapter (Courtney \& Etchegary, 2003) and at the CES national conference for those who participate as finalists (Courtney \& Etchegary, 2003; Seasons \& Myers, 2003). Finalists also receive a one-year membership in the Canadian Evaluation Society, providing access to professional development and networking opportunities. 
The benefits of the competition extend beyond students: coaches have an opportunity to improve teaching and mentorships skills by supporting students in the case competition (Seasons \& Myers, 2003). Specifically, mentorship has been found to be important in supporting the development of competencies among student evaluators (Dillman, 2012; Levin-Rozalis \& Rosenstein, 2003), and the case competition creates an opportunity for students to receive one-on-one mentoring from an evaluator who can help students build connections between theory and practice and provide valuable feedback and resources during the preparation process.

\section{SURVEY OF PARTICIPANTS}

As part of the celebration of the 20th anniversary of the competition, a group of case competition organizers and past participants conducted a survey of former competition participants. The purpose of this survey was to explore participants' experience with the competition, their subsequent involvement in evaluationrelated activities, and the impact of the competition on their personal and professional development. Findings of the survey were presented and discussed at the 2016 CES Annual Conference in St. John's, Newfoundland. This practice note describes the survey results, focusing particularly on the impact of the competition on past participants, and discusses ideas for moving the competition forwards.

\section{SURVEY METHODS AND DATA ANALYSIS}

Of the 1,132 past participants listed in the case competition database, 768 had a valid email address on file and were sent an email containing a link to a web-based questionnaire and an invitation to respond. Two reminder emails were sent. Notification of the survey was also posted to the CES website, which reached eight additional past participants. The bilingual e-survey was pilot tested with five past participants and included 12 mandatory close-ended and one optional openended question examining participation in the case competition (i.e., frequency, year, province/territory, finalist status), occupation, current location (i.e., in or outside Canada), engagement in program evaluation activities (e.g., worked as an evaluator, taught evaluation courses, been a member of an evaluation society), and extent to which the case competition was fun, was a good learning experience, supported personal growth, had an impact on their career, and was a memorable experience. The final open-ended question asked participants to describe any impacts that participating in the case competition had on their personal or professional development. Findings from the pilot testing of the e-survey led to two changes. First, current location was expanded to identify the province or territory where past participants currently resided, to allow for comparisons between where they currently reside and the province/territory where they competed. Second, the question exploring the value of the case competition was modified to improve clarity and more clearly connect to the objectives of the competition. 
A total of 112 past participants completed the 12-item survey, for a response rate of $14 \%$, which represented $10 \%$ of all past participants. Data from close-ended questions were analyzed with basic descriptive statistics using the Statistical Package for the Social Sciences Version 23, and data from the open-ended question were analyzed using thematic content analysis to identify relevant themes.

\section{SAMPLE REPRESENTATIVENESS}

To explore sample representativeness, we compared responders and non-responders on the following three variables: current CES membership, participation in the final round (yes/no), and whether they competed before or after 2008 (i.e., time elapsed since competing). The year 2008 was selected as the cut-point, as this was the year when the CES National Council assumed responsibility for the competition from the CES National Capital Chapter. CES members and competition finalists were over-represented among survey respondents (see Table 1); therefore, chi-squared and t-tests were used to examine differences between these groups.

While competition finalists were more likely to hold CES membership, there were no significant differences between finalists and non-finalists in their participation in various evaluation-related activities. However, competition finalists reported greater enjoyment in the competition, had stronger memories of the competition, and indicated that the competition had a great impact on their personal development.

As shown in Table 2, compared to non-members, CES members were more likely to participate in a variety of evaluation-related activities, including working as a program evaluator, pursuing further evaluation training or education, and applying for the CES Credentialed Evaluator designation. The overall case competition experience (calculated as an average rating across all five statements) was significantly higher for CES members compared to non-members.

Given these significant differences between CES members and non-members, survey responses were weighted by CES membership status to allow for conclusions to be drawn across the full sample. It was expected that due to the relationship between CES membership and competition finalist status, weighting responses by CES membership should mitigate the disproportionate representation of competition finalists in the respondent group. Using the accepted formula for determining weights (i.e., weight $=\%$ of population $/ \%$ of respondents) yielded a weight of 0.14

Table 1. Comparison of survey respondents to non-respondents

\begin{tabular}{llll}
\hline Variable & Condition & $\begin{array}{l}\text { Respondents } \\
(\boldsymbol{n}=112)\end{array}$ & $\begin{array}{l}\text { Non-respondents } \\
(\boldsymbol{n}=1132)\end{array}$ \\
\hline CES membership & Member & $48.2 \%$ & $6.7 \%$ \\
Participation in final round & Finalist & $51.8 \%$ & $16.4 \%$ \\
Time elapsed since com- & Competed after & $74.1 \%$ & $60.3 \%$ \\
peting & 2008 & & \\
\hline
\end{tabular}




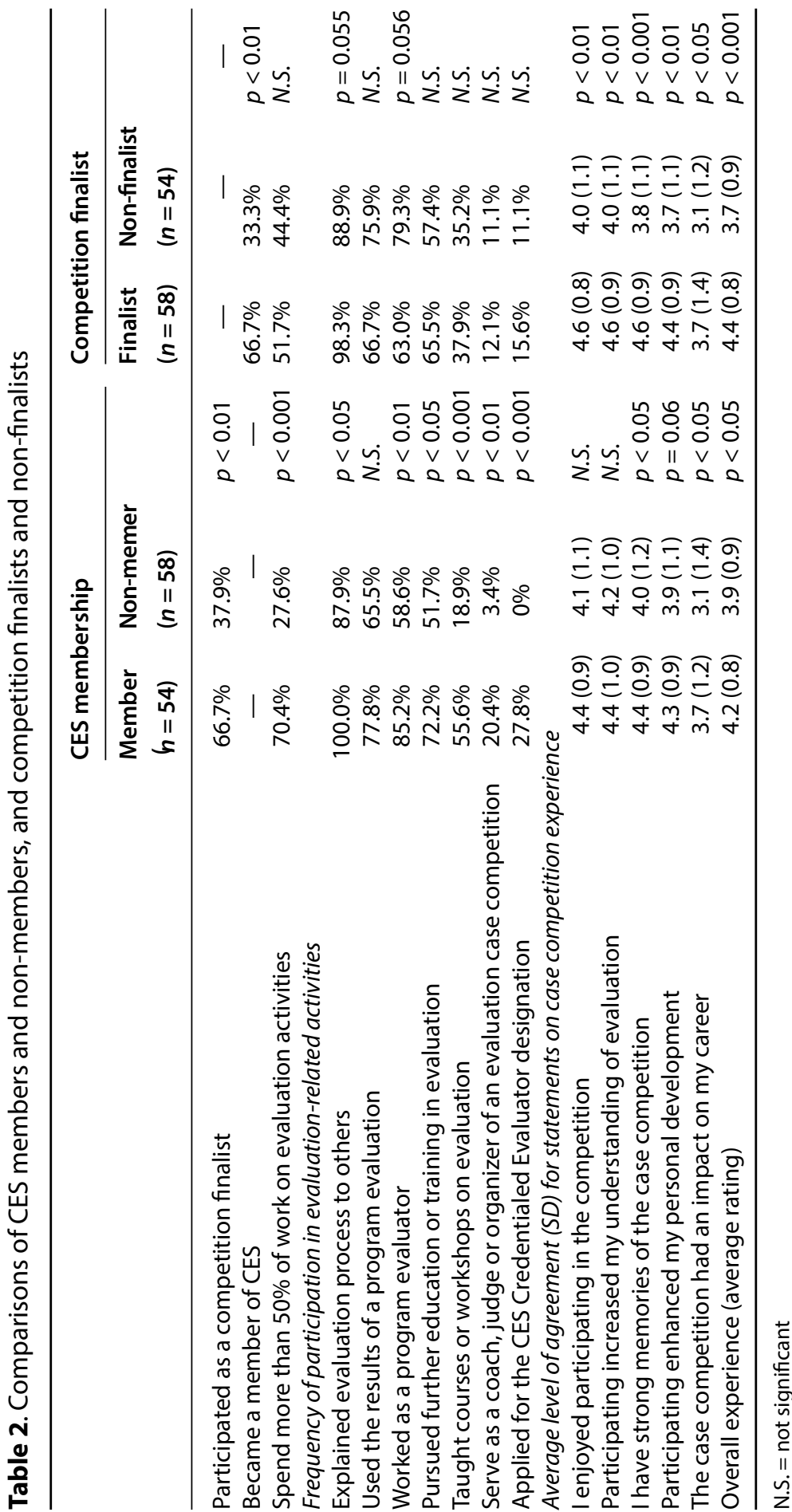


for cases of CES members and a weight of 1.8 for cases of non-CES members. Data for weighted cases are used for the findings presented below.

\section{ABOUT PAST PARTICIPANTS}

Survey findings showed that $82.8 \%$ of respondents competed in the competition only once, and that $39.9 \%$ participated in the final round. Most respondents had competed from Ontario, Newfoundland, and Quebec, with no participants from Manitoba, New Brunswick, Prince Edward Island or the territories (see Figure 1).

Former participants reported working in a variety of sectors, including government $(28.3 \%)$, not-for-profit $(15.3 \%)$, academia $(15.3 \%)$, and for-profit businesses (11.9\%); 5.2\% were self-employed, and $15.3 \%$ were still completing graduate studies. Data suggested that evaluation was an important component of work for many respondents, with $10 \%$ reporting that they spend all their time on evaluation, $29.3 \%$ spending at least half their time on evaluation, and $41.1 \%$ spending less than half their time on evaluation; only $17.8 \%$ reported that they did not currently spend any time on evaluation activities. Furthermore, all participants reported having engaged in evaluation-related activities since participating in the competition, including giving presentations on evaluation (88.7\%), using the results of a program evaluation $(66.3 \%)$, or working as a program evaluator (60.4\%; see Table 3).

\section{IMPACT OF THE CASE COMPETITION}

Findings indicate that the case competition was generally an enjoyable and educational activity that increased participants' understanding of evaluation (see Table 4).

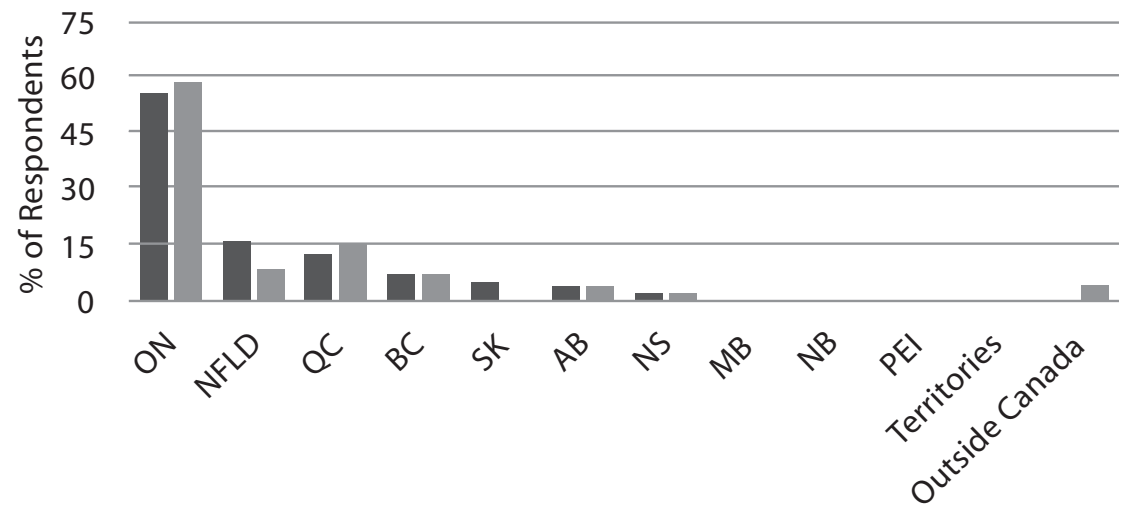

Competition Location $\quad$ Current Location

Figure 1. Competition and current location of past case competition participants 
Table 3. Evaluation-related activities since participating in the competition

\begin{tabular}{ll}
\hline Evaluation-related activity & $\begin{array}{l}\text { \% of weighed } \\
\text { cases }(\boldsymbol{n}=\mathbf{1 1 2})\end{array}$ \\
\hline $\begin{array}{l}\text { Explained evaluation process to others in conversation or presen- } \\
\text { tations }\end{array}$ & 88.7 \\
Used the results of a program evaluation & 66.3 \\
Worked as a program evaluator & 60.4 \\
Pursued further evaluation or training in the field of evaluation & 53.1 \\
Been a member of an evaluation society & 35.5 \\
Taught courses or workshops on evaluation & 21.4 \\
Served as a coach, judge, or organizer for an Evaluation Case & 4.6 \\
competition & \\
Applied for the CES Credentialed Evaluator designation & 1.9 \\
\hline
\end{tabular}

Table 4. Level of agreement to statements on case competition experience

\begin{tabular}{llc}
\hline Statement & $\begin{array}{l}\text { Mean level of } \\
\text { agreement (SD) }\end{array}$ & Range \\
\hline I enjoyed participating in the case competition & $4.16(1.02)$ & $1-5$ \\
Participating increased my understanding of evaluation & $4.19(1.03)$ & $1-5$ \\
I have strong memories of the case competition & $3.99(1.10)$ & $1-5$ \\
Participating enhanced my personal development & $3.94(1.04)$ & $1-5$ \\
The case competition had an impact on my career & $3.21(1.31)$ & $1-5$ \\
\hline
\end{tabular}

${ }^{a}$ Level of agreement rated on a five-point likert scale ( $1=$ strongly disagree; $5=$ strongly agree).

Seventy-eight percent of participants agreed or strongly agreed that participating enhanced their personal development and half agreed or strongly agreed that the case competition had a positive impact on their career.

A total of 49 participants provided a narrative of the personal or professional impacts of participating in the case competition. Nineteen participants described how the competition created opportunities for them to learn about evaluation concepts and methodologies, apply their classroom skills in a realworld setting, and gain practical evaluation experience that supplemented their academic program. For example, one participant described how participating in the case competition helped them "gain an understanding of the variety of programs and organizations that an evaluator might work with and the types of evaluation needs of those clients." Two other participants explained that the mentorship from their coach helped them refine their abilities to develop evaluation proposals and plans, and as a result they felt more confident in their skills as an evaluator. The benefits of teamwork were also described by 12 participants who noted that experience allowed them to learn how to collaborate as a team, 
leverage the strengths of teammates, and expand their professional network of student evaluators.

Five past participants described how the case competition fostered greater interest in the field of evaluation. Specifically, one participant discussed how their experience "piqued my interest in program evaluation and has led my career and professional development to focus on evaluation." Another student similarly noted that after the case competition, they were "bitten by the evaluation bug $[\ldots]$ and have been a full-time evaluator ever since." One participant described how their most "memorable experience was being told after the final round that the evaluation design [my team] proposed in our presentation was similar to the actual design that had been implemented [by the program]. That really boosted my confidence and contributed to my desire to pursue evaluation as a career."

Although one individual did not feel the case competition had any impact on their job prospects, nine others felt the experience was useful when looking for employment and gave them a competitive edge during interviews. For instance, one individual described how they relied on their experience in the case competition when asked to evaluate a case scenario during a job interview, while another reported that a potential employer was aware of the competition and brought it up in a job interview. Another participant discussed how they felt more prepared for employment post-graduation, noting that the competition "provided me with the skills and experience to do [...] evaluation in my current position."

One student who participated as a finalist described the positive experience they had at the conference and how they "felt accepted and supported by the CES community, and appreciated the amount of interest there was in the case competition by those already working in the field." Two other finalists indicated they have since become involved in other aspects of the case competition. Specifically, one described how they were participating as a student coach, and another reported participating in organizing the event and noted that this involvement helps "contribute to the next generation of evaluators."

Although the case competition was frequently described as an invaluable experience that was a highlight of graduate studies, two respondents found the experience unmemorable, and five described negative experiences. Specifically, two individuals felt that their coach did not offer enough support, and as a result, learning was limited. Two others reported disappointment in the quality and extent of feedback they received from the judges. Another individual stated they were "forced to participate in the competition to meet a program requirement."

The seven individuals who reported negative or unmemorable case competition experiences participated in the competition only once and none were finalists. Four reported spending no time on evaluation and only two reported spending more than $50 \%$. Although five reported being a member of an evaluation society in the past, none were current members of the CES. Six reported explaining evaluation to others, five indicated they had worked as a program evaluator in the past, and four reported using evaluation findings. 


\section{DISCUSSION}

The findings from this survey indicate that the CES Student Evaluation Case Competition was a positive experience that appears to yield many benefits for participating students. Past participants indicated that the competition promoted teamwork, created camaraderie, and built confidence as an evaluator. The competition was reported to have a strong effect on participants' understanding of evaluation concepts and methods, with many former participants describing how the intensive, hands-on experience enhanced their ability to create and write an evaluation plan, identify program stakeholders and associated needs, articulate program theory, select evaluation methodologies, and present results. Davies and MacKay (2014) argue that there is still uncertainty as to what types of training can adequately prepare students for a career in evaluation. There is, however, general agreement among instructors of program evaluation that experience, such as planning an evaluation, is a critical component of evaluation training (e.g., Chouinard \& Boyce, 2017; Davies \& MacKay, 2014). According to the survey responses received from past participants, the case competition may be one such way in which students can meaningfully engage in evaluation activities while also receiving direct feedback on their work from experienced evaluators. By focusing on technical skills needed for evaluation (e.g., creating logic models, designing evaluation questions, identifying appropriate data collection methods), the case competition aligns with a new approach to teaching introductory evaluation principles (Chouinard \& Boyce, 2017). Importantly, as students may participate multiple times, the competition gives students opportunity to think like an evaluator with diverse cases and prepare them for carrying out evaluations in practica or work settings.

Many former participants reported contributing to the advancement of evaluation by using evaluation results in their work, or explaining basic evaluation principles to colleagues. In some instances, former participants pursued additional coursework and training in evaluation, taught evaluation, and/or became members of the CES. The CES members who responded to our survey were more likely than non-members to report engaging in evaluation-related activities, such as being employed as a program evaluator and/or working towards obtaining the CES Credentialed Evaluator designation. Overall, CES members were more likely to agree that they had strong memories of their times participating in the case competition and were more likely to report that participating in the competition had a positive impact on their career.

Several past participants have pursued work as a program evaluator and, in at least some instances, believed that competing in the case competition and learning from their coach made them better equipped to fulfill their role as an evaluator. These findings are in line with recent research showing that mentorship is one of the most valuable experiences in evaluation education (Dillman, 2012). Our survey findings demonstrate that the case competition offers mentorship not only from experienced faculty (Seasons \& Myers, 2003) but also from upper-year graduate students who have participated in the competition in the past (Williamson 
et al., 2016). Showcasing mentorship opportunities of the case competition may increase student interest in the competition and encourage upper-year students to participate again, or become involved as a student coach.

While several respondents felt their résumé was strengthened from of their participation in the case competition, it is not known how many potential employers in the field of evaluation are aware of the case competition or use it for potential recruitment opportunities. Indeed, past participants indicated that the competition supported the development of several competencies that evaluation employers look for, including skills in knowledge and application of evaluation theory, presentations, project planning, report writing, and evaluation and research design (Dewey et al., 2008). To increase awareness of the case competition and associated benefits to potential employers, finalists in the case competition should consider highlighting these competencies on their application (e.g., see Stevahn, King, Ghere, \& Minnema, 2005), and including their team submissions on their résumé or their online professional profiles.

Engagement in the case competition among former participants after competing was relatively low, with less than $2 \%$ of the weighted sample serving as a case competition coach, organizer, or judge. Ongoing engagement with former participants may have several benefits, including increasing the profile of the case competition among potential employers or helping identify potential program evaluations that can serve as the basis for the case. Former participants may also wish to support student teams as a co-coach with university/college faculty, or serve as a mock judge during the preparation process.

There are several provinces where few, if any, colleges or universities have participated in the competition. Enhancing the role of CES provincial chapters within the case competition may be one strategy to promote participation in these provinces (Courtney \& Etchegary, 2003). Ongoing engagement with past participants who may be working in those provinces may be beneficial at fostering "case competition ambassadors" who can work with the CES chapters and/ or local colleges/universities to promote the case competition and/or support a team. Given the substantial benefits that participation can bring to students, and the capacity of the competition to promote awareness of evaluation as a discipline, the time may be right for a concerted effort to broaden the competition's reach across the country.

Although we were interested in reaching all past participants, we did not have valid emails for $30 \%$ of previous participants. Of those with valid emails, only $14 \%$ responded. Thus, our final survey sample represented only $10 \%$ of past case competition participants, limiting our ability to generalize our findings to the full case-competition population. It could be that those who responded to the survey were willing to participate because they had greater interest in evaluation. Therefore, even after accounting for CES membership status in our analyses, it is possible that the findings do not accurately reflect the views or activities of the other $90 \%$ of the case competition population who did not participate in our survey. An annual follow-up survey for participants and coaches may be a useful 
tool to enhance our understanding of the personal and professional impact of the competition, and identify ways we can continue to develop the case competition to better prepare emerging evaluators for success in the field.

\section{CONCLUSIONS}

We believe that the findings from this survey enhance our understanding of the impact of the Student Evaluation Case Competition over its 20-year history. At the time the survey data were collected, there had been 1,132 student participants from seven provinces. Of the former participants who completed the survey, many are still active members of the evaluation community. Overall, the results of the survey reflect that the case competition gives students the opportunity to apply and develop their skills in program evaluation and build solid experience that can help students transition into a career in their chosen field. Our findings provide evidence for the continued support of the case competition as an investment in the future of young evaluators.

\section{ACKNOWLEDGEMENTS}

A special thank you goes out to the students, coaches, and other members of the evaluation community for their support of the Canadian Evaluation Society Student Evaluation Case Competition.

\section{REFERENCES}

Chouinard, J. A., \& Boyce, A. (2017). The impact of practice on pedagogy: Reflections of novice evaluation teachers. Canadian Journal of Program Evaluation, 32(2), 280-287. https://doi.org/10.3138/cjpe.31130

Courtney, B., \& Etchegary, H. (2003). CES case competition: A Newfoundland and Labrador chapter perspective. Canadian Journal of Program Evaluation, 18(1), 107-111.

Davies, R., \& MacKay, K. (2014). Evaluator training: Content and topic valuation in university evaluation courses. American Journal of Evaluation, 35(3), 419-429. https:// doi.org/10.1177/1098214013520066

Dewey, J. D., Montrosse, B. E., Schröter, D. C., Sullins, C. D., \& Mattox, J. R., II (2008). Evaluator competencies: What's taught versus what's sought. American Journal of Evaluation, 29(3), 268-287. https://doi.org/10.1177/1098214008321152

Dillman, L. M. (2012). Evaluator skill acquisition: Linking educational experiences to competencies. American Journal of Evaluation, 34(2), 270-285. https://doi. org/10.1177/1098214012464512

Galport, N., \& Azzam, T. (2016). Evaluator training needs and competencies. American Journal of Evaluation, 38(1), 80-100. https://doi.org/10.1177/1098214016643183

Levin-Rozalis, M., \& Rosenstein, B. (2003). A mentoring approach to the one-year evaluation course. American Journal of Evaluation, 24(2), 245-259. https://doi.org/10.1016/ s1098-2140(03)00023-7 
Nykiforuk, C., Gavin, T., Yessis, J., Spencer, A., Lauzon, N., Pearce, N., \& Cyarto, L. (2003). Students' perspective of the CES case competition. Canadian Journal of Program Evaluation, 18(1), 101-106.

Obrecht, M., Porteous, N., \& Haddock, B. (1998). Casing out evaluation: Expanding student interest in program evaluation through case competitions. Canadian Journal of Program Evaluation, 13(2), 129-134.

Seasons, M., \& Myers, A. M. (2003). Reflections on the CES Case Competition: The coaches' perspective. Canadian Journal of Program Evaluation, 18(1), 113-118.

Stevahn, L., King, J. A., Ghere, G., \& Minnema, J. (2005). Evaluator competencies in university-based evaluation training programs. Canadian Journal of Program Evaluation, 20(2), 101-123.

Trevisan, M. S. (2004). Practical training in evaluation: A review of the literature. American Journal of Evaluation, 25(2), 255-272. https://doi.org/10.1016/j.ameval.2004.03.002

Williamson, L. E. A., Robertson, D. W., Gibson, K. A. V., Heimlick, M., Sangster, S. L., \& Lawson, K. L. (2016). Evaluate this! A case for developing evaluation competencies. Canadian Journal of Program Evaluation, 31(1), 82-90.

\section{AUTHOR INFORMATION}

Christine Sheppard is a PhD candidate in the School of Public Health and Health Systems at the University of Waterloo, specializing in aging, health, and wellbeing. She was a finalist in the CES student evaluation case competition in 2014 and 2015, and the winner of the CESEF Student Excellence advancing Evaluation Knowledge (SEEK) award in 2015.

Ashley Baker is a graduate from Memorial University of Newfoundland, where she completed her postgraduate studies in applied research and program evaluation. She is a former finalist in the CES student evaluation case competition in 2015.

Petra Lolic is currently an executive coordinator at Doctors of BC. She has experience in health-care evaluation, policy, and strategy. She is driven by her interest in health-system transformation. Petra obtained her Master's of Public Health from the School of Population and Public Health at the University of British Columbia and was part of UBC's winning CES student evaluation case competition team in 2014.

Shilpa Soni is a graduate from the School of Public Health and Health Systems at the University of Waterloo. She was a finalist in the CES student evaluation case competition in 2014 and 2015.

Bea Courtney recently retired from a career in evaluation, program and policy development, and policy research in both the public and private sectors. A long-time member of the Canadian Evaluation Society, she led the organization of the CES-CESEF Student Evaluation Case Competition over the past decade. She is a recipient of the CES awards for service to the society and contribution to evaluation in Canada. 